\title{
O MESILATO DE IMATINIBE COMO TRATAMENTO PARA INIBIR A PROLIFERACÃO DAS CÉLULAS NEOPLÁSICAS EM PACIENTES COM LEUCEMIA MIELOIDE CRÔNICA
}

\author{
Matias Nunes Frizzo' \\ Alline Pastorio Dick ${ }^{2}$ \\ Josielli Trachynski ${ }^{3}$
}

\begin{abstract}
RESUMO
A Leucemia Mieloide Crônica (LMC) é uma doença mieloproliferativa crônica caracterizada por uma translocação equilibrada entre os cromossomos 9 e 22, que envolve a fusão dos genes BCR/ABL, sendo este rearranjo conhecido como o Cromossomo Philadelphia (Ph). É uma neoplasia com incidência de 1-2 casos por 100 mil adultos, e é responsável por 15\% de todas as leucemias. Esta doença progride ao longo de três fases: fase inicial crônica (FC), fase acelerada (FA) e fase final chamada de crise blástica (CB). Atualmente existem várias estratégias de tratamento adotadas para a LMC Ph+, dentre elas transplante de células tronco, utilização de bussulfano, hidroxiureia, IFN- $\square$ e inibidores da tirosino-quinase (imatinibe, nilotinib, dasatinib e busotinib). 0 mesilato de imatinibe é um inibidor de primeira geração capaz de inibir a proliferacãa das células de diferentes linhagens da LMC e das células progenitoras hematopoiéticas. Essa droga tem mostrado boa eficácia em todas as fases da doença, particularmente nos pacientes com diagnóstico recente de LMC em fase crônica. Os inibidores de segunda geracão mostram-se eficazes e seguros no tratamento em todas as fases, nos pacientes que falharam com a terapia do imatinibe. No presente artigo realizou-se uma pesquisa bibliográfica com material indexado, publicado a partir do ano 2000. A LMC não é uma doença curável com o tratamento medicamentoso, no entanto por meio do tratamento com os inibidores da tirosino quinase apresenta um índice elevado de sobrevida total
\end{abstract}

Palavras-chave: Leucemia Mieloide Crônica. Mesilato de Imatinibe. Glivec. BCR/ABL positivo.

\begin{abstract}
Chronic myeloid leukemia (CML) is a chronic myeloproliferative disorder characterized by a balanced translocation between chromosomes 9 and 22, which involves the fusion of the BCR/ABL genes, and this rearrangement known as the Philadelphia chromosome (Ph). It is a neoplasm with an incidence of $1-2$ cases per 100,000 adults, and accounts for $15 \%$ of all leukemias. This disease progresses through three stages: initial chronic phase (CP), accelerated phase (AP) and final phase called blast crisis (PB). Currently, there are several treatment strategies adopted for $\mathrm{Ph}+\mathrm{CML}$, including stem cell transplantation, use of busulfan, hydroxyurea, IFN- $\square$ and tyrosine kinase inhibitors (imatinib, nilotinib, and dasatinib busotinib). Imatinib mesylate is a first generation inhibitor capable of inhibiting the proliferation of cells of different lineages of hematopoietic of CML and progenitor cells. This drug has shown good efficacy in all phases of the disease, particularly in patients with newly diagnosed CML in chronic phase. The second generation inhibitors are effective and safe in the treatment at all stages, in patients who have failed therapy with imatinib. In this article, we performed a literature search with indexed material published after 2000. CML is not a curable disease with drug treatment, however through treatment with tyrosine kinase inhibitors have a high rate of overall survival.
\end{abstract}

Keywords: Chronic Myeloid Leukemia. Imatinib Mesylate. Gleevec. BCR/ABL positive.

\footnotetext{
${ }^{1}$ Doutor em Biologia Celular e Molecular PUC-RS. Professor Adjunto do Departamento de Ciências da Vida na Unijuí. matias. frizzo@unijui.edu.br

2 Biomédica egressa da CNEC-Iesa. allinedick9@hotmail.com

3 Biomédica egressa da CNEC-Iesa. josieli.px@hotmail.com
} 
A Leucemia Mieloide Crônica (LMC) era considerada uma doença fatal até a introdução de imatinibe (também conhecido como Glivec), que revolucionou a sua terapia, transformando a LMC em uma doença crônica (Trela; Glowacki; Bbasiak, 2014). A Leucemia Mieloide Crônica (LMC) é uma neoplasia mieloproliferativa com uma incidência de 1-2 casos por 100 mil adultos, e é responsável por $15 \%$ dos casos de leucemia diagnosticada em adultos (Jemal, 2010). A idade média do diagnóstico desta patologia é de 55 a 60 anos, com menos de $10 \%$ dos casos em pacientes com idade inferior a 20 anos (Vivona, 2013).

A Leucemia Mieloide Crônica (LMC) é uma doença mieloproliferativa crônica de caráter clonal, caracterizada pela presença do Cromossomo Philadelphia $(\mathrm{Ph})$, o qual resulta numa translocação equilibrada entre os cromossomos 9 e 22 (Funke et al., 2005; Thielen et al., 2011). Na translocação $\mathrm{t}(9: 22)$, o gene ABL associa-se a uma porção de um gene no cromossomo 22, denominado BCR (Barboza et al., 2000).

Em condições normais, o gene BCR codifica uma proteína com função relacionada à regulação do processo de sinalização e divisão celular, enquanto o gene ABL (cromossomo 9) codifica uma proteína tirosino-quinase que participa da regulação do ciclo celular e da resposta a estresse genotóxico (Goloni et al., 2013). O gene quimérico (BCR-ABL), por sua vez, codifica uma nova proteína com atividade tirosino-quinase, que desencadeia a proliferação descontrolada das células na LMC (Di Bacco et al., 2000; Laurent et al., 2001).

A LMC foi a primeira neoplasia associada com uma lesão genética, com o Cromossomo Philadelphia $(\mathrm{Ph})$ constituindo o marcador citogenético dessa doença, descoberto em 1960 por Nowell e Hungerford, e posteriormente descrito por Rudkin, em 1973 (Dorta et al., 2011). O cromossomo Ph não é restrito à LMC, sendo também encontrado em leucemia linfoblástica aguda (LLA); $5 \%$ em pacientes infantis e $25 \%$ em adultos. Em LMC Ph positivo, a translocação é encontrada em todas as linhagens celulares hematopoiéticas, mas menos frequente em células B e T (Ichihara; Pagnano, 2004).
Esta doença progride ao longo de três fases: uma fase inicial crônica (FC) com duração de 3 5 anos; uma fase acelerada (FA), que dura de $6-$ 18 meses, e a fase final chamada de fase blástica (FB) ou aguda da leucemia, com duração de 3-6 meses (Santos; Marrone, 2014). A classificação da Internacional Boné Marrow Transplant Registry (IBMTR) propôs alguns índices para caracterizar as fases: dentre eles, as anormalidades citogenéticas adicionais ao Cromossomo Philadelphia, como trissomia do cromossomo 8 , trissomia do cromossomo 19 , isocromossomo $17 \mathrm{q}$ e novas translocações ou deleções (Sawyers et al., 2002).

O surgimento do imatinibe, droga inibidora da tirosino quinase (TKI) Abl, fez com que ocorresse uma revolução na possibilidade do tratamento da LMC nos últimos anos. A partir de 1999 foi divulgada a utilização deste medicamento como a primeira linha terapêutica para a LMC (Jesus, 2007). Foi aprovado para o uso em pacientes com LMC em fase aguda, fase acelerada ou em fase crônica resistentes ou altamente intolerantes ao IFN- $\alpha$ (Deininger et al., 2014). Além disso, graças à introdução do mesilato de imatinibe no tratamento da LMC observou-se diminuição dos sintomas da doença, aumento na expectativa de vida e os eventos adversos nos pacientes que utilizaram esta droga são mínimos, com menor incidência de sintomas gastrointestinais e cãibras (Lopes; Abreu, 2009). O monitoramento da doença (por meio do acompanhamento laboratorial) é uma das principais estratégias para avaliar a resposta à terapia e detectar precocemente as recidivas (Dobbin; Gadelha, 2002).

No Brasil, dados do Datasus demonstram que, nos últimos seis anos, houve incremento de $40 \%$ dos procedimentos de alta complexidade em oncologia autorizados, o que representou aumento de $63 \%$ dos gastos com quimioterapia ambulatorial do câncer. No caso específico da LMC, o aumento de procedimentos ambulatoriais autorizados e de custos nesse mesmo período é ainda maior, da ordem de $46 \%$ e $307 \%$, respectivamente. Este incremento deu-se principalmente pela introdução, em 2001, do imatinibe para o tratamento dos pacientes na rede pública. Nesta avaliação, contudo, não foi conside- 
rada a redução dos gastos públicos decorrentes da diminuição no número de transplantes de medula óssea para a LMC (Nonino, 2008).

Por outro lado, inibidores de tirosino-quinase de segunda geração têm sido desenvolvidos com mais potência do que o imatinibe, com a finalidade de diminuir a chance de desenvolvimento de resistência (Delamain; Conchon, 2008). Novas drogas, como Desatinibe, Busotinibe e Nilotinibe, estão sendo desenvolvidas para que sejam utilizadas em pacientes que apresentaram resistência ou intolerância à terapêutica prévia, incluindo o imatinibe, ou que efeitos adversos intensos tenham sido observados no paciente. A composição destas novas drogas baseia-se na inibição específica da expressão gênica da doença e tem a função de bloquear a atividade quinase da proteína $\mathrm{Bcr} / \mathrm{Abl}$ levando à remissão da LMC (Lopes; Abreu, 2009). Nesse contexto, o presente estudo tem como objetivo avaliar o tratamento da leucemia mieloide crônica com mesilato de imatinibe, sua eficácia, riscos, graus de intolerância/ resistência e o surgimento de fármacos de segunda geração.

\section{LEUCEMIA MIELOIDE CRÔNICA - LMC}

Normalmente existe um equilíbrio entre a proliferação, diferenciação e renovação das células-tronco hematopoiéticas. Em pacientes com Leucemia Mieloide Crônica este equilíbrio encontra-se alterado, decorrente de uma proliferação e diferenciação aumentada e anormal (Barboza et al., 2000). A taxa de incidência da LMC por sexo nos Estados Unidos é aproximadamente 2 por 100.000 habitantes para homens e cerca de 1,1 por 100.000 pessoas para mulheres. A menor incidência é na Suécia e na China (cerca de 0,7 por 100.000 habitantes), e a maior incidência ocorre na Suíça e nos Estados Unidos (cerca de 1,5 por 100.000 habitantes) (Bocchia et al., 2005).

A Leucemia Mieloide Crônica (LMC) é uma doença clonal maligna caracterizada por uma excessiva proliferação da linhagem mieloide (Fase Crônica - FC), seguida por uma perda progressiva da diferenciação celular (Fase Acelerada - FA) e terminando num quadro de leucemia aguda (Fase Blástica - FB). Esta doença é associada a uma anormalidade citogenética específica, o Cromossoma Philadelphia $(\mathrm{Ph})$, que resulta de uma translocação recíproca entre os braços longos dos cromossomas 9 e 22, isto é, a $t(9 ; 22)$ e leva à formação de um novo gene leucemia-específico, o BCR-ABL, detectável por polymerase-chain-reaction (PCR) (Santos; Marrone, 2014).

Em 1960, Nowell e Hungerford detectaram uma consistente anormalidade cromossômica, denominada posteriormente de cromossomo Philadelphia $(\mathrm{Ph})$, e identificado como $22 \mathrm{q}-$ em indivíduos que apresentavam esplenomegalia maciça associada à leucocitose idiopática (Goldman; Melo, 2003). Em 1973, Rowley observou que o cromossomo $\mathrm{Ph}$ era resultante de uma translocação recíproca envolvendo também o cromossomo 9. Atualmente a anormalidade é descrita citogeneticamente como $t$ (9;22) (q34;q11). Em 1980 constatou-se que o cromossomo $\mathrm{Ph}$ apresentava uma única fusão gênica, denominada BCR/ABL. Esta sequência híbrida de DNA é resultante da união do proto-oncogene ABL (Abelson), presente no cromossomo 9, e do gene BCR (do inglês, Breakpoint Cluster Region), do próprio cromossomo 22. Este gene quimérico, $\mathrm{BCR} / \mathrm{ABL}$, é traduzido em uma proteína de 210 $\mathrm{kDa}$ (p210), com atividade aumentada de tirosino-quinase, apresentando significativa importância na patogênese da doença (Bocchia et al., 2005).

No início da doença (fase crônica), que pode durar vários anos, os caracteres patológicos são considerados aparentemente "benignos". Alguns pacientes são assintomáticos, mas outros apresentam fadiga, fraqueza, dores de cabeça, irritabilidade, febre, suor noturno e perda de peso. O diagnóstico é realizado pelos achados clínicos, citogenéticos e hematológicos do sangue periférico e medula óssea (Bergantini et al., 2005).

O sangue periférico apresenta, inicialmente, leucocitose $(50.000$ a 300.000/ $\mu 1)$, com desvio à esquerda e predomínio de neutrófilos segmentados, havendo aparecimento de células granulocíticas mais imaturas, como mielócito e metamielócito, 
e poucos mieloblastos e promielócitos. A maioria dos pacientes tem basofilia e eosinofilia. Ao diagnóstico, a hemoglobina pode ser normal ou pode haver discreta anemia (normocítica/normocrômica), e o número de plaquetas é geralmente normal ou elevado, havendo plaquetopenia ao diagnóstico em $5 \%$ dos casos. Caracteristicamente, não se observa displasia na fase inicial da doença, o ácido úrico encontra-se elevado, a fosfatase alcalina intraleucocitária é baixa em $90 \%$ dos pacientes na fase crônica, elevando-se na Fase Acelerada e na Crise Blástica (Kanegae, 2006).

A LMC evolui da fase crônica para um período de doença mais avançada e de difícil controle, chamado de Fase Acelerada (FA), e desta para a Crise Blástica (CB). Algumas vezes pode ocorrer a evolução da Fase Crônica diretamente para a Crise Blástica (Almeida et al., 2009). A fase acelerada (FA) surge após um período variável do diagnóstico, de poucos meses a vários anos, e caracteriza-se pelo aumento de blastos (10\% a $19 \%)$ na medula óssea e no sangue periférico, leucocitose e basofilia ( $\geq 20 \%$ ), anemia e trombocitopenia persistente $(<100.000 \mu 1)$. Clinicamente, o paciente torna-se refratário ao tratamento empregado na fase crônica e pode apresentar progressão da hepato-esplenomegalia (Bergantini et al., 2005). Pacientes com LMC raramente são diagnosticados em FA e, com o sucesso dos inibidores da tirosino-quinase, o número de pacientes que evoluem da FC para a FA tende a se reduzir drasticamente (Bortolheiro; Chiattone, 2008).

Posteriormente, a doença evolui para a fase blástica, definida hematologicamente pelo aumento de blastos leucêmicos (linfoides ou mieloides) no sangue periférico e/ou medula óssea (mais de $20 \%$ ). Nesse estágio da doença muitos pacientes evoluem para o óbito entre três e seis meses (Bergantini et al., 2005). Em 70\% dos casos de Crise Blástica, a transformação é mieloide, e em $20 \%$ a $30 \%$, linfoide, raramente bifenotípica ou bilinhagem (Jamur, 2005). Nesta fase, mais de $50 \%$ dos doentes evoluem para um quadro semelhante ao da Leucemia Mieloblástica Aguda (LMA); 30\% para um quadro similar ao da Leucemia Linfoblástica Agudas (LLA), com blastos de linhagem pré-B, e
$10 \%$ com blastos de linhagem eritroide, tornando-se uma fase de curta duração e a mais agressiva de todas as outras (Hugues et al., 2014).

Sureda et al. (2003) identificaram que cerca de $30 \%$ dos pacientes desenvolvem a crise blástica diretamente a partir da fase crônica. Diferentemente da fase crônica, a crise blástica apresenta uma resposta não muito satisfatória na maioria das vezes às manobras terapêuticas utilizadas. Atualmente existem várias estratégias de tratamento adotadas para a $\mathrm{LMC} \mathrm{Ph}+$, entre elas o controle no número de leucócitos (bussulfano, hidroxiureia), a eliminação das células $\mathrm{Ph}$ positivas por substituição de células alogênicas (TCT - Transplante de Células-Tronco), por supressão não específica do clone neoplásico (IFN- $\alpha$ ) e também a utilização de mesilato de imatinibe (Jamur, 2005; Jesus, 2007).

A terapêutica das LMCs até os anos 80 era insatisfatória, inicialmente utilizava-se o tratamento com arsênico e radioterapia, que controlavam apenas os sintomas. Nos anos 50 o tratamento de escolha era o bussulfano, que somente apresentava melhora na qualidade de vida, não alterando positivamente o tempo de sobrevida global dos pacientes. Além disso, os agentes alquilantes utilizados eram significativamente tóxicos, podendo predispor a progressão para uma fase avançada da doença; posteriormente ainda foi utilizada a hidroxicarbamida, mas que também apresentava problemas com sua toxicidade (Goldman, 2007).

A hidroxiureia (HY) e o bussulfano (BU) são os dois principais agentes citostáticos utilizados no tratamento da LMC. São usados durante a fase crônica e têm por finalidade diminuir a massa tumoral existente e o risco de complicações trombóticas decorrentes da leucocitose. Atualmente, devido à alta sensibilidade das células da LMC às drogas quimioterápicas orais, tem-se conseguido bons resultados em pacientes tratados com $\mathrm{HY}$ e BU, obtendo-se remissão hematológica em cerca de $90 \%$ dos pacientes. Essas drogas, no entanto, não alcançam um efeito desejado em relação à remissão citogenética ou molecular e quando o fazem é por 
um período de curta duração. Sendo assim, não se consegue evitar que a doença progrida com este tipo de medicamento (Santos, 2007).

O primeiro agente com o qual obteve-se uma remissão citogenética foi com o interferon-a, entre 1980-2000, considerada a droga de escolha para os pacientes não elegíveis ao Transplante de Células Hematopoéticas Progenitoras (TCHP). O transplante ainda é o tratamento de escolha, e apresenta como meta a cura da LMC, com remissão molecular (Goldman, 2007).

Com tratamentos à base de interferon-a, em torno de $60 \%$ dos pacientes alcançavam uma resposta citogenética maior com menos de $35 \%$ das células Philadelphia positivas, e $89 \%$ dos pacientes ainda mantinham-se após 18 anos da doença em fase crônica. Os interferons possuem um amplo efeito biológico e nele se incluem a inibição da proliferação celular, a regulação da expressão de citocinas e a modulação de vigilância imune. Dessa forma, o tratamento com INF- $\alpha$ tem como principal resultado a remissão citogenética (Jamur, 2005). A proporção de pacientes refratários ao INF- $\alpha$ é alta, uma população mínima responde ao tratamento cerca de $10 \%-20 \%$ dos casos. Além disso, este medicamento prejudica muito o dia a dia dos pacientes devido aos seus efeitos colaterais severos (Hehlmann; Berger; Hochhaus, 2005).

Na porta do século 21, ou melhor, a partir de 1998, o tratamento de primeira linha da LMC é com um inibidor da tirosino-quinase. O primeiro inibidor da tirosino-quinase a chegar ao mercado foi o imatinibe. Tanto com o TCHP como com o imatinibe o alvo do tratamento é a remissão molecular (Druker et al., 2001), no entanto a decisão de realizar TCHP existe em uma variedade de momentos: falha em se conseguir remissão hematológica, citogenética ou molecular, ou quando se perde a melhor resposta conseguida ou por progressão da doença para uma fase avançada (Aranha, 2008).

Geralmente, a principal causa da morte nos pacientes com LMC são as infecções ou hemorragias, relacionadas, respectivamente, à neutropenia e trombocitopenia progressivas. Estes achados podem surgir secundariamente à mielofibrose progressiva, a qual pode levar ao esgotamento da hematopoese e, portanto, à morte por insuficiência medular (Sawyers et al., 2002).

\section{MESILATO DE IMATINIBE}

O mesilato de imatinibe é um inibidor da tirosina quinase capaz de inibir a proliferação das células de diferentes linhagens da LMC e das células progenitoras hematopoiéticas. Essa droga, liberada para uso clínico desde 1998, é administrada por via oral, com doses terapêuticas entre 300 e $800 \mathrm{mg} /$ dia, com boa tolerância e poucos efeitos colaterais. Tem mostrado boa eficácia em todas as fases da doença, particularmente nos pacientes com diagnóstico recente de LMC em fase crônica (Barbany; Höglund; Simonsson, 2002).

O gene híbrido BCR-ABL aumenta significativamente a expressão da proteína tirosina-quinase, que é responsável pela transferência de um grupo fosfato extraído de uma molécula de ATP para outros grupos proteicos. As proteínas, então, fosforiladas, são responsáveis pelas alterações fisiopatológicas encontradas na LMC (Druker et al., 2001). Basicamente, o imatinibe funciona como um inibidor competitivo do ATP, pois ele se liga nos sítios de fosforilação do BCR-ABL, bloqueando a atividade tirosina-quinase (Savage; Antman, 2002).

Os testes clínicos de fase I começaram em 1998, e o grupo escolhido para o tratamento com o imatinibe incluía pacientes com LMC na fase crônica que eram refratários ou intolerantes ao IFN- $\alpha$. Em seguida, o estudo foi expandido para pacientes em crise blástica. Os pacientes foram tratados com imatinibe em doses que variavam entre $25 \mathrm{mg}$ até $1.000 \mathrm{mg}$ diariamente. Na dosagem a partir de $300 \mathrm{mg} / \mathrm{dia}$ observou-se resposta clínica mais satisfatória. Entre os pacientes de fase crônica que haviam falhado com IFN- $\alpha, 53$ de 54 (98\%) atingiam a Resposta Hematológica Completa $(\mathrm{RCH})$. Em pacientes com crise blástica mieloide, 21 de 38 (55\%) apresentaram resposta clínica (Druker et al., 2001). Com esses dados de alta resposta e baixa toxicidade, em 10 de março de 2001 o Food and Drug Administration (FDA) aprovou a terapia com imatinibe em pacientes com LMC em todos os estágios (Deininger, 2003).

A terapia inicial recomendada para pacientes com LMC em fase crônica é o Imatinib $400 \mathrm{mg} / \mathrm{dia}$ (Baccarani et al., 2009). O Imatinib tem-se mostrado melhor que a terapia com INF (terapia padrão 
anteriormente) no que diz respeito à remissão da doença e à sobrevivência do paciente (Druker et al., 2006). Depois de oito anos, o Imatinib foi descontinuado por eventos adversos em $6 \%$ dos pacientes, por falta de eficácia em $22 \%$, e por outras razões, em 17\% (Deininger et al., 2014).

Apesar dos resultados significativamente positivos do tratamento da LMC com imatinibe, 10\% dos pacientes se tornam resistentes ao tratamento (Melo; Hughes; Apperly, 2003). A resistência à mesilato de imatinib é observada em cerca de 10\%$15 \%$ dos pacientes e pode ser classificada como primária ou secundária, de acordo com o tempo de aparecimento. A resistência primária (intrínseca) é a falta de eficácia a partir do início do tratamento com mesilato de imatinib e a resistência secundária (adquirida) é definida como uma resposta inicial seguida de uma perda de eficácia com o tempo de exposição ao mesilato de imatinib (Olshen et al., 2014).

A resistência ao imatinibe provoca falha para obtenção de uma Resposta Hematológica Completa em três meses, nenhuma resposta citogenética aos 6 meses, falha para obtenção de resposta citogenética maior aos 12 meses e falha para obtenção de resposta citogenética completa aos 18 meses. Já a intolerância ao imatinibe é constatada em pacientes que descontinuaram a terapia com imatinibe em decorrência de eventos adversos (Santos, 2007).

\section{FÁRMACOS DE SEGUNDA GERAÇÃO}

O nilotinibe é uma nova aminopiridina, que é um inibidor ATP-competitivo da atividade da proteína tirosino-quinase do BCR-ABL, prevenindo a ativação das vias mitogênico e antiapoptótica dependentes do BCR-ABL, levando à morte do fenótipo do BCR-ABL. Dados de estudos pré-clínicos demonstram que o nilotinibe atinge concentrações intracelulares mais elevadas do que o imatinibe e inibe a atividade da tirosino-quinase do BCR-ABL induzindo a apoptose em concentrações mais baixas do que o imatinibe (Delamain; Conchon, 2008).
Outro fármaco de segunda geração é o dasatinib, um novo agente que foi aprovado para o tratamento de adultos com LMC em Fase Crônica, Fase Acelerada ou Crise Blástica resistentes ou intolerantes ao tratamento prévio com imatinibe. Diferente do imatinibe, o fármaco inibe as formas ativas e inativas da molécula BCR-ABL (Delamain; Conchon, 2008). Além disso, o dasatinib é indicado também no tratamento de doentes adultos com leucemia linfoblástica aguda (LLA) positiva para o $\mathrm{Ph}+\mathrm{e}$ com LMC linfoblástica, com resistência ou intolerância à terapêutica prévia, no entanto a toxicidade hematológica deste fármaco pode ser observada em pacientes em fase de doença mais avançada (Lopes; Abreu, 2009).

O bosutinibe é, similarmente ao dasatinib, um duplo inibidor ativo contra BCR/ABL da LMC. Em contraste ao imatinibe e ao dasatinibe, o bosutinibe não tem atividade inibitória o que pode reduzir os efeitos colaterais da droga; além disso, é capaz de atuar inibindo algumas mutações do gene BCR-ABL. A atividade inibitória do bosutinibe está em estágio de desenvolvimento, sendo testada nas fases I e II da LMC (Deininger et al., 2014).

Os inibidores de segunda geração mostram-se eficazes e seguros no tratamento da LMC em todas as fases, nos pacientes que falharam com a terapia do imatinibe. Os eventos adversos relatados até então foram considerados leves a moderados e de fácil manejo com a redução de dose ou interrupção temporária da droga. Apenas encontrou-se a retenção hídrica (edema periférico, pleural, pulmonar) em $<1 \%$ dos pacientes (Delamain; Conchon, 2008).

\section{ACOMPANHAMENTO LABORATORIAL DA LMC}

Segundo Chauffaille (2009), o mesilato de imatinibe tornou-se a primeira opção terapêutica para a fase crônica da LMC. A dose preconizada é de 400 $\mathrm{mg} / \mathrm{dia}$, por via oral. Sua ação é avaliada pela: resposta hematológica completa (RHC), que constitui o desaparecimento dos sintomas, da esplenomegalia e a normalização do hemograma; resposta citogenética, que é graduada conforme a porcentagem 
de células Ph-positivas residuais na medula óssea; e resposta molecular, que quantifica o número de transcritos, por reação em cadeia da polimerase por transcriptase reversa em tempo real quantitativa (Rq-PCR), conforme descrito no Quadro 1.

Quadro 1 - Tipos de resposta hematológica, citogenética e molecular

\begin{tabular}{|c|c|}
\hline \multicolumn{2}{|r|}{ HEMATOLÓGICA } \\
\hline \multirow{3}{*}{ Completa } & $\begin{array}{c}\text { Normalização do sangue periférico com } \\
\text { leucócitos }<10.000 / \mu \mathrm{L} ; \text { plaquetas }<450.000 / \\
\mu \mathrm{L} ;\end{array}$ \\
\hline & $\begin{array}{l}\text { Ausência de células imaturas, mielócitos, } \\
\text { promielócitos ou blastos no sangue periférico; }\end{array}$ \\
\hline & $\begin{array}{c}\text { Ausência de sinais e sintomas da doença com } \\
\text { desaparecimento do baço palpável; }\end{array}$ \\
\hline \multirow{4}{*}{ Parcial } & Idem ao anterior, exceto: \\
\hline & Presença de células imaturas; \\
\hline & $\begin{array}{c}\text { Plaquetas }>450.000 / \mu \mathrm{L} \text {, mas } 50 \% \text { menor que } \\
\text { a contagem prévia ao diagnóstico; }\end{array}$ \\
\hline & $\begin{array}{c}\text { Persistência de esplenomegalia, mas 50\% } \\
\text { menor que ao diagnóstico; }\end{array}$ \\
\hline \multicolumn{2}{|r|}{ CITOGENÉTICA } \\
\hline Completa & Ausência de $\mathrm{Ph}$ \\
\hline Maior & $0 \%$ a $35 \%$ de metáfases com $\mathrm{Ph}$ \\
\hline Parcial & $1-34 \%$ de metáfases com $\mathrm{Ph}$ \\
\hline Menor & $35 \%$ a $90 \%$ de metáfases com $\mathrm{Ph}$ \\
\hline \multicolumn{2}{|r|}{ MOLECULAR } \\
\hline Completa & Ausência de transcritos $\mathrm{BCR} / \mathrm{ABL}$ \\
\hline Maior & Redução RNAm BCR/ABL > $3 \log$ \\
\hline
\end{tabular}

Fonte: Adaptado de Chauffaille, 2009.

Há vários estudos que relatam alterações laboratoriais após o uso do mesilato de imatinibe em pacientes com LMC. No hemograma, as citopenias, particularmente neutropenia e trombocitopenia foram um achado consistente em todos os estudos, sugerindo frequência mais elevada com doses $\geq 750$ $\mathrm{mg} /$ dia (estudo de fase I), no entanto a ocorrência de citopenias também foi claramente dependente do estágio da doença. Em pacientes com LMC recentemente diagnosticada, as citopenias foram menos frequentes que nos outros pacientes com LMC. A duração média dos episódios neutropênicos e trombocitopênicos geralmente limitou-se por 2 a 3 semanas e por 3 a 4 semanas, respectivamente. Estes efeitos podem ser habitualmente tratados, quer com uma redução da dose, quer com uma interrupção do tratamento, mas podem, em casos raros, levar a sua interrupção permanente. Em pacientes pediátricos com LMC, a toxicidade observada mais frequente foi neutropenia, trombocitopenia e anemia. Geralmente ocorreram nos primeiros meses de terapia (Hugues et al., 2014).

A elevação grave das transaminases $(<5 \%)$ ou bilirrubina $(<1 \%)$ tem sido vista em pacientes com LMC e foi geralmente controlada com uma redução ou interrupção da dose (a duração média destes episódios foi de aproximadamente uma semana). O tratamento foi interrompido permanentemente, devido a anormalidades laboratoriais hepáticas, em menos de $1 \%$ dos pacientes com LMC. Houve casos de hepatite citolítica e colestática, bem como insuficiência hepática; com evolução fatal em alguns destes casos. O fosfato sérico baixo (hipofosfatemia) foi observado de forma relativamente comum entre todas as indicações; no entanto, a origem e a significância clínica deste achado não foram estabelecidas (Hugues et al., 2014).

\section{MATERIAIS E MÉTODOS}

No presente artigo realizou-se uma pesquisa bibliográfica baseada na coleta de dados relativos aos seguintes descritores: Leucemia Mieloide Crônica, Mesilato de Imatinibe, fármacos de segunda geração e acompanhamento laboratorial.

A seleção de artigos obedeceu, ainda, alguns critérios, como material bibliográfico indexado, publicado a partir de 2000. Para a realização desse estudo foram utilizadas as seguintes bases eletrônicas: PubMed, Lilacs, SciELO e PNAS, nas quais inicialmente foram obtidos 27.153 artigos. Após o 
refinamento com os descritores, tempo de publicação e relevância dos trabalhos selecionou-se 53 artigos científicos.

\section{DISCUSSÃO}

É de caráter consensual que a LMC é caracterizada por uma translocação equilibrada genética, $\mathrm{t}(9,22)$ (q34; q11.2), que envolve a fusão do oncogene Abelson (ABL) do cromossomo 9q34, com a região de agrupamento do ponto de interrupção do gene (BCR) no cromossomo 22q11.2, sendo este rearranjo conhecido como o cromossomo Philadelphia (Ph). A consequência molecular da translocação é a geração de um oncogene de fusão BCR-ABL, que por sua vez, traduz-se em uma oncoproteína de BCR/ABL (Jabbour; Kantarjian, 2014).

Os dados mais atuais da Leucemia Mieloide Crônica (LMC) apontam que esta neoplasia mieloproliferativa apresenta uma incidência de 1-2 casos por 100 mil adultos, e é responsável por menos de $15 \%$ dos casos diagnosticados de leucemia em adultos (Jabbour; Kantarjian, 2014). No Rio Grande do Sul, num estudo retrospectivo, Fassina et al. (2003) estimaram uma incidência de 0,6 caso em 100 mil habitantes por ano, com uma média de idade de 42 anos ao diagnóstico, e uma maior frequência no sexo masculino, semelhante à descrita no estudo da Santa Casa de São Paulo (Bortolheiro, 2007). Nos três estudos realizados por Pallotta et al. (2006), os pacientes com maior prevalência de LMC eram do sexo masculino.

$\mathrm{Na}$ LMC, as células precursoras hematopoéticas malignas são mais resistentes à apoptose do que as células normais, devido à expressão dessa proteína, que prolonga a sobrevida da célula e aumenta exponencialmente a proliferação celular. Essa neoplasia é, atualmente, considerada um dos melhores e mais importantes modelos de estudo da hematopoese leucêmica. Além disso, é de consenso entre os pesquisadores que o rearranjo BCR-ABL (proteína tirosino-quinase) desempenha um papel crítico na fisiopatogênese da doença. A enzima tirosina quinase proveniente do BCR-ABL existe apenas nas células cancerosas e não em células normais. Dessa forma, o mesilato de imatinibe funciona como uma forma de terapia direcionada na qual apenas os clones leucêmicos são destruídos pela ação da droga. Nesse sentido, é inegável que o imatinibe foi uma das drogas que revolucionaram as terapias contra o câncer por isso do seu potencial para uma ação dirigida/específica.

Tal como todos os inibidores de tirosino-quinase, o imatinibe funciona inibindo uma enzima tirosino-quinase. A enzima tirosino-quinase de BCR-ABL existe apenas nas células cancerosas e não é encontrada em células saudáveis, dessa maneira o imatinibe funciona como uma forma de terapia direcionada, pois apenas são afetadas as células tumorais. Neste sentido, o imatinibe foi uma das primeiras terapias contra o câncer para demonstrar o potencial para tal ação orientada, sendo frequentemente citado como um paradigma para a investigação em terapêutica antitumoral.

Com o advento do Mesilato de Imatinib os pacientes com Leucemia Mieloide Crônica (LMC) em fase crônica estão vivendo mais em função da terapia de inibidores da tirosino-quinase, dando ênfase a questões relacionadas com a carga de sintomas e qualidade de vida (QV). Um importante fator associando a essa terapia, no entanto, é o seu potencial de eventos adversos com a terapia de longo prazo, podendo resultar em ajustes de dose, interrupção do tratamento ou a não adesão, os quais podem afetar negativamente a eficácia do tratamento e qualidade de vida dos pacientes (Cella; Nowinski; Frankfurt, 2014).

$\mathrm{Na}$ maioria dos estudos realizados com pacientes diagnosticados com LMC, observam-se diversas alterações hematológicas, citogenéticas e moleculares após o início do tratamento com o Mesilato de Imatinibe. Recomenda-se, porém, o acompanhamento regular (pelo menos a cada 2 meses) da função hepática (transaminases, bilirrubina, fosfatase alcalina, Gama-GT) nos pacientes. Entre os efeitos adversos causados pelo Mesilato de Imatinibe e relatados até então foram considerados leves a moderados e de fácil manejo com a redução de dose ou interrupção temporária da droga. Em relação 
aos eventos adversos hematológicos, neutropenia e plaquetopenia, ocorreram em $28 \%$ dos casos. Os eventos adversos não hematológicos mais frequentes foram erupção cutânea, náusea, cefaleia, prurido e fadiga (Delamain; Conchon, 2008).

Um estudo alemão analisou dados de tratamento em pacientes recém-diagnosticados com LMC - BCR/ABL positivo na fase crônica. Os pacientes foram comparados em relação à dose de imatinibe utilizada (400 mg/dia ou $800 \mathrm{mg} / \mathrm{dia})$, idade ( $\geq 65$ anos ou $<65$ anos), resposta ao tratamento, eventos adversos e taxas de progressão e sobrevivência. Foram avaliados 784 pacientes. Entre eles, 382 utilizavam Mesilato de Imatinibe 400mg/dia (110 pacientes $-29 \%$ - com idade $\geq 65$ anos) e 402 utilizavam a dose de $800 \mathrm{mg} / \mathrm{dia}$ ( 83 pacientes $-21 \%$ - também com idade $\geq 65$ anos). Os pacientes mais velhos com uso de imatinibe $800 \mathrm{mg} /$ dia alcançaram grande remissão molecular tão rápido quanto os pacientes mais jovens; enquanto que com imatinibe dose padrão (400mg/dia), os pacientes mais velhos conseguiram remissões muito mais tarde do que os pacientes mais jovens (Proetel et al., 2014).

Já um tratamento envolvendo uma faixa etária mais jovem avaliou um total de 51 pacientes pediátricos com LMC recém-diagnosticada e não previamente tratada em fase crônica. Participaram do estudo clínico de fase II, aberto, multicêntrico de braço único e foram tratados com Mesilato de Imatinibe (Glivec) $340 \mathrm{mg} / \mathrm{m}^{2} / \mathrm{dia}$. O tratamento levou a uma resposta rápida em pacientes pediátricos com LMC recém-diagnosticada com RHC de $78 \%$ após 8 semanas de terapia e uma resposta citogenética completa (RCC) de 65\%, (comparável aos resultados em adultos) após 3 a 10 meses de tratamento (Hughes et al., 2014).

No Brasil o uso do imatinibe na população pediátrica ainda não foi discutido no âmbito da Comissão Nacional de Ética na Pesquisa (Conep), do Conselho Nacional de Saúde. Sabe-se que uma comissão de ética na população pediátrica é muito mais rigorosa do que na população adulta. De fato, os Comitês de Ética em Pesquisa só aceitam estudos na população pediátrica após a conclusão dos estudos em adultos, salvo se a indicação terapêutica for exclusiva para esse grupo. A segurança e a eficácia do Mesilato de Imatinibe em pacientes com menos de 18 anos de idade ainda não foram plenamente estabelecidas, e sequer se definiu a dose adequada deste medicamento para o doente não adulto (Suttorp; Millot, 2010; Dobbin; Gadelha, 2002). Por não diferir biologicamente da doença do adulto, o paciente pediátrico apresenta manifestações clínicas e evolutivas semelhantes. A principal diferença observada na apresentação da doença foram as contagens leucocitárias mais elevadas no grupo pediátrico em relação às descritas em adultos (Rault et al., 2013).

Em relação ao tempo de resposta ao imatinibe na população o estudo de Pallotta et al. (2006) na fase pré-Mesilato de Imatinibe (MI) o paciente apresentava 66.100 leucócitos $/ \mathrm{mm}^{3}$. No terceiro mês de uso do medicamento já se observou uma queda na contagem de células para 53.000 leucócitos $/ \mathrm{mm}^{3}$. No sexto mês a contagem foi de 3.800 leucócitos $/ \mathrm{mm}^{3}$ e assim se manteve aproximadamente nesses valores até o décimo segundo mês. Tsao, Kantarijian e Talpaz (2002), em sua pesquisa demonstraram que de 54 pacientes em Fase Crônica, 98\% obtiveram o mesmo resultado citado anteriormente, ou seja, conseguido a remissão hematológica.

O tratamento tem como principal objetivo obter uma resposta hematológica completa até os 3 meses, resposta citogenética mínima $(<95 \% \mathrm{Ph})$ até os 6 meses, resposta citogenética maior $(<35 \%$ $\mathrm{Ph})$ até os 12 meses, resposta citogenética completa $(0 \% \mathrm{Ph})$ até os 18 meses e resposta molecular maior $(<0,1 \%)$ até os 18 meses. Aos pacientes com LMC recomenda-se monitorar adequadamente o tratamento por meio de hemogramas, exames citogenéticos, moleculares (PCR quantitativo) e, ainda, exames que avaliam a função hepática e renal.

As taxas de resposta hematológica completa (RHC), resposta citogenética maior (RMC) e resposta citogenética completa (RCC) no tratamento de primeira linha (Mesilato de Imatinibe) foram estimadas usando o método de Kaplan-Meier, para os quais as não respostas foram censuradas na data 
do último exame. Usando este método, as taxas de resposta acumulativa estimada para o tratamento com Glivec são mostradas na Quadro 2.

Quadro 2 - Resposta acumulativa estimada para tratamento com Glivec

\begin{tabular}{|cccc|}
\hline $\begin{array}{c}\text { MESES EM } \\
\text { TERAPIA }\end{array}$ & RHC (\%) & RCM (\%) & RCC (\%) \\
\hline 12 meses & 96,4 & 84,6 & 69,5 \\
24 meses & 97,2 & 89,5 & 79,7 \\
36 meses & 97,2 & 91,1 & 83,6 \\
48 meses & 98,2 & 91,9 & 85,2 \\
60 meses & 98,4 & 91,9 & 86,7 \\
84 meses & 98,4 & 91,9 & 87,2 \\
\hline
\end{tabular}

Fonte: Adaptado de Al-Hadiya; Barhkheit; Abd-Elgalil, 2014.

A monitoração de pacientes com LMC exige, no mínimo, hemograma com contagem diferencial, mielograma com citogenética e biologia molecular do sangue periférico para medir os níveis do transcrito BCR-ABL. O hemograma com contagem diferencial deve ser realizado com 1-2 semanas durante os três primeiros meses até a remissão hematológica completa (RHC) ter sido atingida. Depois, mensalmente. O mielograma com citogenética nos $3^{\circ}$ e $6^{\circ}$ meses, depois a cada 6 meses até que seja atingida a RCC. Ao atingir esta, dever-se-á manter a quantificação do BCR-ABL a cada três meses. Em caso de RMC, realizar mielograma com citogenética anualmente.

Três inibidores da tirosino-quinase (imatinibe, nilotinibe e dasatinibe) foram aprovados pela Food and Drug Administration para o tratamento de pacientes recém-diagnosticados com LMC em Fase Crônica (LMC-FC). Os ensaios clínicos com inibidores de segunda geração relataram respostas significativamente melhores e mais rápidas. Embora os inibidores de segunda e terceira geração sejam potentes e específicos para BCR-ABL, eles apresentam perfis farmacológicos exclusivos e padrões de resposta em relação a diferentes características dos pacientes, como comorbidades, o estágio da doença e o estado mutacional do gene BCR/ABL. $O$ transplante alogênico permanece uma opção terapêutica importante para pacientes com LMC-FC que falharam, no mínimo, em dois inibidores da tirosino-quinase, e para todos os pacientes em fase avançada da doença (Jabbour; Kantarjian, 2014).

Comparado com o Mesilato de Imatinibe (MI), o dasatinibe é 300 vezes mais potente in vitro em relação à proteína $\mathrm{BCR} / \mathrm{ABL}$. Pacientes em $\mathrm{FC}$ resistentes ao MI foram distribuídos aleatoriamente para receber $140 \mathrm{mg}$ de dasatinibe $(\mathrm{n}=101)$ ou 800 mg de imatinibe ( $n=49)$, e após 15 meses de acompanhamento, a Resposta Hematológica Completa foi alcançada em $93 \%$ e $82 \%$ dos casos, respectivamente. O Dasatinibe resultou em maior taxa de Resposta Citogenética Completa e de Resposta Molecular Maior quando comparada à alta dose de MI (Kantarjian et al., 2007).

O nilotinibe é uma molécula modificada, 20 vezes mais potente in vitro que o MI. Foi aprovado pelo FDA americano em 2007 para uso em LMC $\mathrm{Ph}+$ em FC ou FA, resistentes ou intolerantes ao MI. Num estudo realizado por Kantarjian et al. (2011), o nilotinibe foi usado em 280 pacientes com $\mathrm{LMC} \mathrm{Ph}+$ em FC, após falha ou intolerância ao MI, na dose de $400 \mathrm{mg}$ (duas vezes ao dia), que induziu Resposta Citogenética Completa em 48\% dos casos após seis meses de acompanhamento. Efeitos adversos foram leves a moderados, e ainda não foi aprovado para o tratamento da Crise Blástica (CB).

Assim, as opções terapêuticas para pacientes com LMC recentemente diagnosticados continuam a evoluir, novos fármacos, assim como o nilotinibe e o dasatinibe, têm sido aprovados para o tratamento de primeira linha. O diagnóstico e o tratamento da LMC demandam acesso a uma estrutura laboratorial para a realização de exames imprescindíveis, como é o caso de citogenética de medula óssea e PCR quantitativo para BCR/ABL. Esta estrutura, contudo, não está disponível em todos os centros de onco-hematologia nacionais. Destaca-se, portanto, a necessidade de uma cooperação entre centros para que todos os pacientes tenham acesso ao diagnóstico e tratamento precoces e uma monitorização adequada sobre a resposta ao tratamento. 


\section{CONCLUSÃO}

Até há poucos anos as LMCs levavam os pacientes a óbito em quatro anos, aproximadamente. Hoje, no entanto, há pelo menos uma possibilidade de cura ou aumento de sobrevida para a maioria dos casos. O Mesilato de Imatinibe é altamente ativo e tem um nível de toxicidade aceitável quando administrado sozinho para o tratamento da LMC. Comprovadamente, induz altas taxas de resposta hematológica, citogenética e molecular, com um índice elevado de sobrevida total.

Atualmente a LMC não é uma doença curável com o tratamento medicamentoso. $\mathrm{O}$ transplante de medula óssea é a única modalidade curativa de tratamento, por induzir remissão molecular com a eliminação dos transcritos BCR-ABL. O Mesilato de Imatinibe é a terapia de escolha para pacientes diagnosticados com Leucemia Mieloide Crônica (LMC), mas, apesar dos diversos resultados positivos, não é capaz de erradicar completamente a doença, podendo ocorrer resistência ao tratamento. A segunda geração de medicamentos inibidores da tirosino-quinase apresenta-se como opção importante para casos de falha, resistência ou intolerância ao imatinibe.

\section{REFERÊNCIAS}

AL-HADIYA, B. M.; BARHKHEIT, A. H.; ABD-ELGALIL, A. A. Imatinib mesylate. Profiles Drug Subst Excip Relat Methodol, v. 39, n. 1, p. 265-297, 2014.

ALMEIDA, A. et al. Recomendações para o diagnóstico, tratamento e monitorização da leucemia mielóide crônica. Acta Médica Portuguesa, v. 22, n. 1, p. 537-544, 2009.

ARANHA, F. Leucemia mielóide crônica: transplante de medula óssea. Revista Brasileira de Hematologia e Hemoterapia, Campinas, v. 30, n. 1, p. 41-46, 2008.
BACCARANI, M. et al. Chronic myeloid leukemia: An update of concepts and management recommendations of European LeukemiaNet. Journal of Clinical Oncology, v. 27, n. 35, p. 6.041-6.051, dec. 2009.

BARBANY, G.; HÖGLUND, M.; SIMONSSON, B. Complete molecular remission in chronic myelogenous leukemia after imatinib therapy. The New England Journal of Medicine, v. 347, n. 7, p. 539540, 2002.

BARBOZA, L. et al. Análise dos transcritos da translocação $\mathrm{t}(9 ; 22)$ em leucemia mielóide crônica. Revista Brasileira de Hematologia e Hemoterapia, Rio de Janeiro, v. 22, n. 2, p. 89-98, maio 2000.

BERGANTINI, A. et al. Leucemia mielóide crônica e o sistema Fas-FasL. Revista Brasileira de Hematologia e Hemoterapia, São José do Rio Preto, v. 27, n. 2, p. 120-125, jun. 2005.

BOCCHIA, M. et al. Effect of a p210 multipeptide vaccine associated with imatinib or interferon in patients with chronic myeloid leukaemia and persistent residual disease: a multicentre observational trial. The Lancet, v. 9.460, n. 365, p. 657-662, 2005.

BORTOLHEIRO, T. Avaliação de fatores prognósticos e das respostas hematológica, citogenética e molecular em pacientes com leucemia mielóide crônica tratados com mesilato de imatinibe. São Paulo. 2007. Dissertação (Mestrado) - Faculdade de Ciências Médicas da Santa Casa de São Paulo, 2007.

BORTOLHEIRO, T.; CHIATTONE, C. Leucemia mielóide crônica: história natural e classificação. Revista Brasileira de Hematologia e Hemoterapia, São Paulo, v. 30, n. 1, p. 3-7, mar. 2008.

CELLA, D.; NOWINSKI, C.; FRANKFURT, O. The impact of symptom burden on patient quality of life in chronic myeloid leukemia. Oncology, v. 87, n. 3, p. 133-147, jul. 2014.

CHAUFFAILLE, M. Leucemia mielóide crônica: tratamento baseado em evidências. Diagnóstico e Tratamento, v. 14, n. 2, p. 62-65, 2009.

DEININGER, M. Cytogenetics studies in patients on imatinib. Seminars in Hematology, v. 40, n. 1, p. 50-55, 2003.

DEININGER, M. et al. Imatinib $800 \mathrm{mg}$ daily induces deeper molecular responses than imatinib 400 mg daily: results of SWOG S0325, an intergroup 
randomized PHASE II trial in newly diagnosed chronic phase chronic myeloid leukaemia. British Journal of Haematology, v. 164, p. 223-232, 2014.

DELAMAIN, M.; CONCHON, M. Os inibidores de tirosino quinase de segunda geração. Revista Brasileira de Hematologia e Hemoterapia, Campinas, v. 30, n. 1, p. 37-40, fev. 2008.

DI BACCO, A. et al. Molecular abnormalities in chronic myeloid leukemia: deregulation of cell growth and apoptosis. The Oncologist, Cork, v. 5, n. 5 , p. $405-415,2000$.

DOBBIN, J.; GADELHA, M. Mesilato de Imatinibe para tratamento da leucemia mielóide crônica. Revista Brasileira de Cancerologia, Rio de Janeiro, v. 48, n. 3, p. 429-438, ago. 2002.

DORTA, M. et al. Resultados citogenéticos en pacientes con leucemia mieloide crônica. Revista Cubana de Medicina, La Habana, v. 50, n. 4, p. 341-347, abr. 2011.

DRUKER, B. et al. Efficacy and safety of a specific inhibitor of the BCR-ABL tyrosine kinase in chronic myeloid leukemia. The New England Journal of Medicine. Massachusetts, v. 344, n. 14, p. 1.031-1.037, apr. 2001.

DRUKER B. et al. Fiveyear follow-up of patients receiving imatinib for chronic myeloid leukemia. The New England Journal of Medicine, v. 355, $\mathrm{n}$. 23, p. 2.408-2.417, dec. 2006.

FASSINA, K. Estimativa do número de afetados e manejo da leucemia mieloide crônica no Estado do Rio Grande do Sul. Porto Alegre. 2003. Dissertação (Mestrado em Ciências Médicas) - Universidade Federal do Rio Grande do Sul, 2003.

FUNKE V. et al. Therapy of chronic myeloid leukemia with imatinib mesylate in Brazil: A study of 98 case. Revista Brasileira de Hematologia e Hemoterapia, Curitiba, v. 27, n. 3, p. 159-165, set. 2005.

GOLDMAN, J.; MELO, J. Chronic myeloid leukemia: advances in biology and new approaches to treatment. New England Journal of Medicine, v. 349, n. 15, p. 1.451-1.464, 2003.

GOLDMAN, J. How I treat chronic myeloid leukemia in the imatinib era. Blood Journal, London, v. 110, n. 8, p. 2.828-2.837, 2007.
GOLONI, C. et al. Análise do rearranjo BCR/ABL por bandamento GTG e FISH: comparação das frequências ao diagnóstico da LMC. Arquivos de Ciência da Saúde, v. 13, n. 1, p. 7-11, mar. 2013.

HEHLMANN, R.; BERGER, U.; HOCHHAUS, A. Chronic myeloid leukemia: a model for oncology. Annals of Hematology, v. 84, n. 1, p. 487-497, 2005.

HUGHES, T. et al. Deep molecular responses achieved in patients with CML-CP who are switched to nilotinib after long-term imatinib. Blood, v. 124, n. 5, jul. 2014.

ICHIHARA, E.; PAGNANO, K. Mutações de ponto do gene bcr/abl em pacientes com leucemia mielóide crônica resistentes ao mesilato de imatinib (glivec). In: Congresso Interno de Iniciação Científica da Unicamp. 12., 2004.

JABBOUR, E.; KANTARJIAN, H. Chronic myeloid leukemia: 2014 update on diagnosis, monitoring, and management. American Journal of Hematology, v. 89, n. 5, p. 547-556, may. 2014.

JAMUR, V. Estudo citogenético de pacientes com leucemia mielóide crônica tratados com o Mesilato de Imatinibe. 2005. Dissertação (Mestrado em Ciências Biológicas) - Departamento de Genética da Universidade Federal do Paraná, Curitiba, 2005.

JEMAL, A. et al. Cancer statistics. CA: A Cancer Journal for Clinicians, v. 60, n. 1, p. 277-300, jul. 2010.

JESUS, C. Avaliação de parâmetros laboratoriais e clínicos de pacientes portadores de leucemia mielóide crônica submetidos ao tratamento com $\mathrm{Me}$ silato de Imatinibe e sua relação com alterações observadas no Estroma da Medula Óssea. 2007. Dissertação (Mestrado em Farmácia) - Universidade Federal de Santa Catarina, Florianópolis, 2007.

KANEGAE, M. Desenvolvimento de ensaio quimiluminescente baseado na determinação de fosfatase alcalina para diagnóstico diferencial entre leucemia mielóide crônica e reações leucemóides. 2006. Tese (Doutorado em Análises Clínicas) - Faculdade de Ciências Farmacêuticas, Araraquara, 2006.

KANTARJIAN, H. et al. Dasatinib or high-dose imatinib for chronic-phase chronic myeloid leukemia after failure of first-line imatinib: a randomized phase 2 trial. Blood, v. 109, n. 12, p. 5.143-5.150, 2007. 
KANTARJIAN, H., COUTRE, P., CORTES, J., PINILA-IBARZ, J., NAGLER, A., KIMURA, S., OTTMANN, O. Nilotinib (formerly AMN107), a highly selective BCR-ABL tyrosine kinase inhibitor, is effective in patients with Philadelphia chromosome-positive chronic myelogenous leukemia in chronic phase following imatinib resistance and intolerance. Blood, v. 117, n. 4, p. 1.141-1.145, 2011.

LAURENT, E. et al. The BCR gene and Philadelphia chromosome-positive leukemogenesis. Cancer Research, Houston, v. 61, n. 6, p. 2.343-2.355, mar. 2001.

LOPES, N.; ABREU, M. Inibidores de tirosino quinase na leucemia mieloide crônica. Revista Brasileira de Hematologia e Hemoterapia, Uberaba, v. 31, n. 6, p. 449-453, jan. 2009.

MELO, J.; HUGHES, T.; APPERLY, J. Chronic myeloid leukemia. American Society of Hematology. London, p. 132-152, 2003.

NONINO, A. Problemas e perspectivas do tratamento da leucemia mielóide crônica no Brasil. Revista Brasileira de Hematologia e Hemoterapia, v. 30, n. 1, p. 66-69, abr. 2008.

OLSHEN, A. et al. Dynamics of chronic myeloid leukemia response to dasatinib, nilotinib, and highdose imatinib. Journal of the Europeans Hematology Association, 2014.

PALLOTTA, Ronald et al. Tratamento da recidiva da leucemia mielóide crônica após transplante de medula óssea alogênico utilizando mesilato de imatinibe: relato de três casos. Rev. Bras. Hematol. Hemoter, v. 28, n. 2, p.157-160, 2006.

PROETEL, U. et al. Older patients with chronic myeloid leukemia ( $\geq 65$ years) profit more from higher imatinib doses than younger patients: a subanalysis of the randomized CML-Study IV. Annals of Hematology, Germany, v. 93, n. 1, p. 1.1671.176, feb. 2014.

RAULT, L. et al. Chronic myeloid leukemia in children and adolescents: A single center experience from Eastern India. South Asian Journal of Cancer, v. 2, n. 4, p. 260-264, 2013.

SANTOS, C. Tratamento da leucemia mielóide crônica com mesilato de imatinibe no hospital de clínicas de Porto Alegre. 2007. Dissertação (Mestrado em Ciências Médicas) - Universidade Federal do Rio Grande do Sul, Porto Alegre, 2007.
SANTOS, L.; MARRONE, F. Resultados do Mesilato de Imatinibe no tratamento da leucemia mieloide crônica: uma revisão bibliográfica. 2014. Disponível em: <http://revistaseletronicas.pucrs.br/ojs/ index.php/graduacao/article/viewFile/2845/2154>. Acesso em: 26 out. 2014.

SAVAGE, D.; ANTMAN, K. Imatinib Mesylate - A New Oral Targeted Therapy. New England Journal of Medicine, v. 346, n. 1, p. 683-693, 2002.

SAWYERS, C. et al. Imatinib induces hematologic and cytogenetic response in patients with chronic myelogenous leukemia in mteloid blast crisis: results of a phase II study. Blood, v. 99, n. 10, p. 3.530-3.539, 2002.

SUTTORP, M.; MILLOT, F. Treatment of Pediatric Chronic Myeloid Leukemia in the Year 2010: Use of Tyrosine Kinase Inhibitors and Stem-Cell Transplantation. American Society of Hematology, v. 2, n. 1, p. 368-376, dec. 2010.

SUREDA, A. et al. Imatinib mesylate as treatment for blastic transformation of Philadelphia chromossome positive chronic myelogenous leukemia. Journal of hematology, v. 88, n. 11, p. 1.213-1.220, nov. 2003.

THIELEN, N. et al. New insights into the pathogenesis of chronic myeloid leukaemia: towards a path to cure. Netherlands Journal of Medicine, Amsterdam, v. 69, n. 10, p. 430-440, oct. 2011.

TRELA, E.; GLOWACKI, S.; BBASIAK, J. Therapy of Chronic Myeloid Leukemia: Twilight of the Imatinib Era? ISRN Oncology, Lordz, v. 1, n. 1, p. 1-9, jan. 2014.

TSAO, A., KANTARJIAN H., TALPAZ, M. STI571 in chronic myelogenous leukaemia. British Journal of Haematology, v. 119, n. 1, p. 15-24, 2002.

VIVONA, D. Estudo da expressão dos genes ABCB1 e SLC22A1 e sua relação com marcadores de resposta ao mesilato de imatinibe em pacientes com leucemia mieloide crônica. 2013. Tese (Doutorado em Análises Clínicas e Toxicológicas). Universidade de São Paulo, São Paulo, 2013.

Recebido em: 27/10/2014

Aceito em: 29/2/2016 